\title{
Upper Primary School Basic Science Curriculum Materials Development Process in Oromia Regional State, Ethiopia
}

\author{
Bezabih Wondimu $(\mathrm{PhD})$ \\ Ass/ Professor in Curriculum Design and Development \\ BALE -ROBE/ ETHIOPIA
}

\begin{abstract}
The purpose of this study was to explore upper primary school basic science curriculum materials development process in Oromia Regional State, Ethiopia. For the purpose of this study, qualitative research method, more specifically, case study design was used. Non-probability purposive sampling techniques was used to select participants from various groups. To this effect, sample of five basic science curriculum experts were selected and used as a sample of the study. Interview guides and document analysis were employed to gather information. Qualitative data analysis method was used to analyze the data. Qualitative data were analyzed through narrative description and direct quotations of the opinions of the participants. The result of data analyses revealed that curriculum experts from the Oromia Region Education Bureau, representatives from the Ministry of Education, representatives from colleges and universities were involved in the process of curriculum development. However, concerned bodies from primary school teachers, students, parents, who are the main actors of curriculum implementers were not involved in the process of curriculum development in Oromia Regional State. The study also revealed that no clearly defined model was used for the development and the selection of the components of the basic science curriculum in the upper primary in Oromia Regional State. Based on the findings, it is recommended that policy makers and curriculum developers in the region reconsider and revisit the developed upper primary school basic science curriculum materials currently implemented in Oromia regional state.
\end{abstract}

Keywords: Curriculum, Curriculum materials, Curriculum development, Basic science and Upper primary school.

DOI: $10.7176 / \mathrm{JEP} / 10-1-08$

\section{INTRODUCTION}

\section{Background of the study}

Education is a great concern in both developed and developing countries. This is because, education is a cornerstone for the social, economic, political and technological advancement and diversification in all human societies (Lockheed and Verspoor, 1991). According to UNESCO (2000), education serves for all rounded development of an individual and society to acquire new knowledge, skills and insights that enable them to bring about development. Supporting this idea, Prasad (2006:120) asserts that:

"Education is the most powerful tool in the process of national renaissance, transformation of society, as well as, for the development of the individual and modernization based on moral and spiritual values on one hand and on science and technology on the other. For him, education is an instrument of change."

All these purposes of education can only be realized through an effective plan of education generally referred to as the curriculum of the school system (Shiundo and Omulando, 1992; Tyler, 1949; Ornstein and Hunkins, 2004). Therefore, the curriculum needs to be designed in such a way that it reflects the needs and interests of the students and social forces existing in a given society. This is because, a well-planned and organized curriculum provides an opportunity for an individual student to maximize benefits from participation in learning activities. In this scheme, curricula and teaching programs play an indispensable role since they are tools through which expectations of individuals in terms of knowledge, values, and skills to be gained are materialized.

To realize this, the 1994 education and training policy of Ethiopia, devised nine different strategies: curriculum; educational structure; educational measurement and evaluation; teacher's training; language and education; nexus between the education, training research and development; educational support inputs; decentralization of educational organization and management; and educational finance. Among these nine strategies, decentralized educational organization and management, empowered Regional States to pursue their primary school curriculum based on their own objective conditions (TGE, 1994). Specifically, the development of textbooks for the primary education became the responsibility of respective Regional State governments with technical assistance from the Federal Government or Ministry of Education. In the process of curriculum development (syllabus, textbooks and teachers' guide preparation), the relationship of the central authority with the regions also portrayed the types of curriculum development model in the Ethiopian context.

Under this circumstance, all regions in the country begun to develop their own primary school curriculum materials by using their own experts since 1995. As a result of this, the Oromia Regional Education Bureau was vested the responsibility of developing curriculum materials for primary schools. Since then, the region has 
continued to develop its own curriculum materials, especially syllabus, students' textbooks, teachers' guides and manuals, based on the syllabus which was sent from MoE.

\section{Statement of the problem}

Curriculum is the means to achieve the purpose of education. Developing or having a balanced or relevant curriculum is the major and primary means of ensuring quality education. To this end, Tyler (1949) and Taba (1962) state that the quality and relevance of the curriculum materials should be assessed in terms of the extent that educational objectives are formulated and stated, and suitable educational contents and learning experiences are selected and organized which in turn help to achieve the desired ends.

In this regards, quality and relevant curriculum design and development involves the involvement of different stakeholders who are directly or indirectly benefited from the curriculum- participatory approach, and considering the needs and interests of the society and has schemes of necessary elements for implementation and evaluation. So far, there has been no significant and thorough study to assess the stakeholders involved in the primary school basic science curriculum development process in Oromia Region. Hence, an investigation of the stakeholders involved in the primary basic science curriculum development processes in Oromia Regional state, was the main concern of this study.

Furthermore, it is assumed that curriculum development involves making decisions about the curriculum objectives, content, resources, teaching-learning and assessment strategies. This means, it is essential to follow the appropriate process of curriculum design and development in light of the scientific curriculum development procedures, stakeholders' participation, consideration of societal and global realities, consideration of proper competences, and national developmental goals (Taba, 1962). By cascading this general truth, "What were the development stages through which primary school basic science curriculum go in Oromia Regional State? Was another concern of this study.

Although curriculum development is highly a researchable theme only few studies were available in Ethiopia. In this regard, attempts have been made to study only on implementation issues by few researchers: an overall study of the secondary school curriculum implementation (Solomon, 2008); evaluation of primary school English textbook in terms of specific elements of curriculum, language components and skills and cultural elements (Dawit, 1999); assessment of the status of the student centered teaching methods and assessment practices in teaching science in Oromia (Dereje, 2007); and an assessment of school social science curriculum implementation: the case of Geography grade $7-8$ (Ayalew, 2006). However, these studies have some limitations: They have been conducted only on implementation aspects; no one touched the development aspects of the curriculum; or both symoltinousely.

Indeed, all the above facts or rationales mentioned initiated the researcher to investigate the relevance and appropriateness of upper primary school basic science curriculum materials development process in Oromia Regional State, Ethiopia. Hence, to deal with these problems in concrete terms, the following basic basis research questions were raised and need to be answered in the course of the study.

1. Who were participated in the process of curriculum development?

2. What model was used in the process of curriculum development?

3. What were the procedures employed in the development of upper primary school basic science curricula in Oromia Regional State, Ethiopia?

4. What were the major factors affecting the development of basic science curricula in Oromia Regional State, Ethiopia?

\section{Objectives of the study}

\section{General objective of the study}

The general objective of this study was to analyze upper primary school basic science curriculum materials development processes in Oromia Regional State, Ethiopia.

\section{Specific objectives of the study}

In light of the general objective of the study, the following specific objectives guided this study:

1. To identify participates involved in the process of curriculum development.

2. To indicate the model used in the process of curriculum development.

3. To analyze the procedures employed in development of upper primary school basic science curricula in Oromia Regional State, Ethiopia.

4. To identify the major factors affecting curriculum development process basic science curricula in Oromia Regional State, Ethiopia.

\section{Delimitation of the study}

The study was focused on upper primary school basic science curriculum because of the importance attached to 
quality science education. Quality science education is a timely issue because of its link with the economic development of the country. Content wise, it is delimited to a study of the relevance of the materials from perspectives of the procedures followed, behavioural objectives formulated, selection and organization of contents and learning experiences, teaching methods, and assessment and evaluation techniques with the aim of identifying their relationship.

\section{Theoretical and conceptual frameworks of the study Theoretical framework of the study}

Constructivism as a learning theory was used to guide this study. The essential core of constructivism is that learners actively construct their own knowledge and meaning from their experiences. Constructivism is not a unitary theoretical position; rather, it is frequently described as a continuum. The assumptions that underlie this continuum vary along several dimensions and have resulted in the definition of, and support for multiple types of constructivism. This continuum is divided into different broad categories, namely cognitive constructivism and social constructivism (ibid, 2004). Cognitive constructivism, which represents one end of the constructivist continuum where knowledge acquisition is an adaptive process and results from active cognizing by the individual learner. The other category of constructivism is social constructivism. This was the theory of Vygotsky in the late 1970's. Social constructivism according to Vygotsky (1978) emphasizes the social nature of knowledge, and the belief that knowledge is the result of social interaction and language use, and, thus, is a shared, rather than an individual experience.

In line with this, social constructivism has been taken as theoretical framework used for study; with assumption that curriculum development process is technical and social process because the process of curriculum development should pass through the necessary steps or the systematic process which are considered as basic scientific procedures because curriculum is a science in part that requires scientific procedures to plan, implement, and evaluate (McNeil, 1996). If one of the phases is missed or ignored, it can negatively affect other phases thereby creating gaps. Furthermore, the process of curriculum development needs collaborative efforts of many stakeholders like participation of educational experts, teachers, policy makers, students and societies and all other beneficiaries of the curriculum. It requires social networking (Derebssa, 2004). In a nutshell, curriculum development process passes all procedures of curriculum development process (technical) and allowing the participation of different stakeholders (social nature) of curriculum development. Thus, curriculum development process is technical and social in its very nature. Therefore, from the aforementioned discussion, it is viable to be guided by the technical and social theories - social constructivism of curriculum development.

\section{Conceptual framework of the study}

A conceptual framework is the researcher's own position on the problem and gives direction to the study. It is the road map / diagram which shows the variables included in the study. It illustrates the relationships between the independent and dependent variables; which in turn helps to provide a comprehensive understanding of the problem under study (Riechel and Ramey, 2004). The conceptual framework for this study was assembled from a consistent and comprehensive theoretical framework of previous literature, models and other present information, with modifications to suit this particular study; hence, this research is based on the following conceptual framework in Figure 1. 


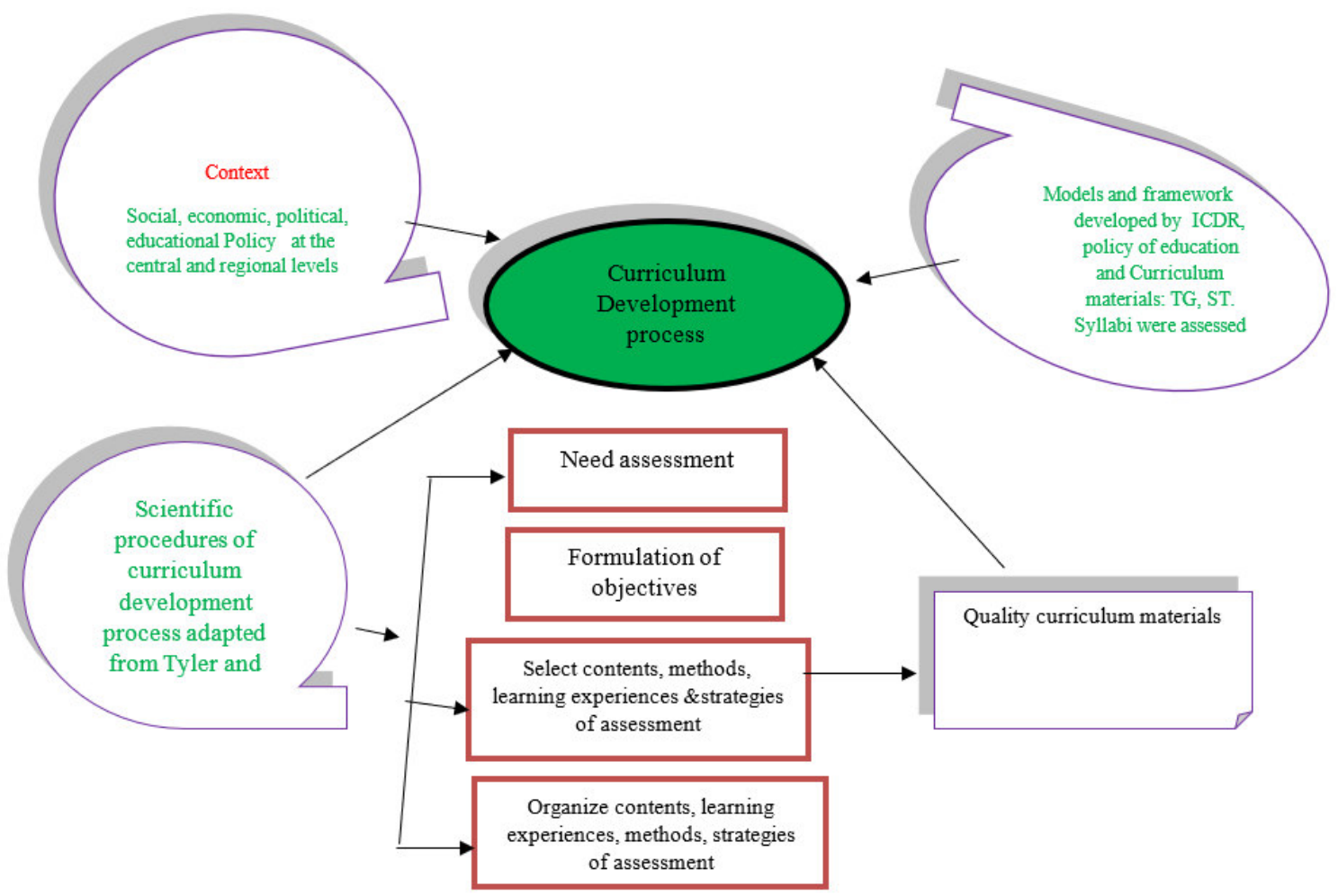

Figure 1. Representation of conceptual framework of the study

This conceptual framework helps to map the curriculum materials development process starting from the regional education bureau to the school level. As indicated in the background of the study, for instance, the central government of Ethiopia has the responsibility of developing the educational policy, curriculum guideline, design the flow chart for each subject and designing a syllabus (TGE, 1994).

The Regional Education Bureau on the other hand, adapts the designed syllabus based on the regional context and develops the curriculum materials, like textbooks and teacher's guide accordingly and implements them in all primary schools in Oromia. The conceptual framework of this study focuses on upper primary school basic science curriculum materials development process at the Oromia Regional State with special reference to the basic theoretical framework of objective model adapted from Tyler and Taba model in line with the curriculum development framework developed by ICDR. In this context, all the procedures and steps followed in adapting the national upper primary school curriculum materials were assessed as per the objective model and the framework used by the ICDR in developing the national curriculum.

\section{Research method of the study}

Based on the objectives of the study and philosophical assumptions which involve the collection and analysis of qualitative data, the researcher used a qualitative research method, as an appropriate method that can help to achieve the objectives of the study. Qualitative research method was selected because it enables the researcher to get a fuller picture and deeper understanding of a phenomenon in a single data and a series of the study (Creswell, 2009:510). More specifically, the qualitative case study design was used to generate qualitative data. In a qualitative case study design, a researcher makes a detailed examination about the single case rather than making general explanations about the population, it examines "how" and "why" questions in a contemporary set of events (Yin, 2003).

\section{Sources of data}

For this research purpose, both primary and secondary sources of data were used. The primary sources of data, the first-hand information, were collected from curriculum experts from the curriculum department of Oromia Education Bureau. Documents (national policy, student's textbooks, statistical abstract and other relevant materials) were taken as the secondary sources of data which in turn complement the primary sources of data.

\section{Population, samples and sampling techniques of the study}

In order to get the necessary information from representative sources, the population of the study were all Oromia Education Bureau curriculum experts. Since because the population under study is found to be finite and homogeneous on the basis of a research setting, subject/respondents' background small sample size were 
used.

In line with this, in order to select appropriate samples for the study, the researcher employed nonprobability purposive sampling techniques to select samples from the population. Thus, science curriculum experts from the department of curriculum in Oromia Regional Education Bureau were selected purposefully. Those officials are deliberately contacted with the assumptions that they have information persistent for the study and had a chance to fully observe what are going on in curriculum development process.

\section{Data collection instruments}

The desired information for the study was gathered through different data collection instruments. To these end, interview guide and document analysis were used to collect data from the respondents. Interview is a commonly used method that helps to gather the required information verbally and in face to face manner (Best and Kahn, 2003:199). Hence, with this understanding, structured a face - to - face interview was held with curriculum experts found in Oromia Regional Bureau to explore the process of curriculum materials development process. In addition, document analysis (national policy, student's textbook and relevant documents) were used in the course of the study.

\section{Methods of data analysis}

Since the study employed qualitative research methods, qualitative data analysis technique was employed. Consequently, the data collected through the interviews and document analysis were analyzed qualitatively to answer basic questions set at the beginning of the study. Finally, the major findings of the study were reported and after which feasible recommendations were forwarded. For so doing, the previously formulated objectives and basic research questions served as a basis for the analyzing the data collected through interview and document analysis.

\section{Ethical considerations}

In order to secure sufficient and pertinent data, due attention was given to ethical issues from the initial formulation of the research problem to the interpretation and reporting the research findings. Thus, a researcher properly treated the informants by applying the commonly known research ethical principles like confidentiality, anonymity, requesting permission, privacy, respect and undertaking to protect the participant identify from any harm before, during and after research process.

\section{Data presentation, analysis and interpretation}

As it has been already mentioned in the preceding sections, the purpose of this study was to investigate the upper primary school basic science curriculum materials development process in Oromia regional state, Ethopia. In this section, therefore, presentation, analysis and interpretation of qualitative data collected through interview and document analysis were presented in line with basic research questions and objectives of the study.

For meeting the ethical principles of anonymity, sampled experts were given the right to choose pseudonyms of their interest and they did so. The pseudonyms chosen by sample respondents themselves were used in the analysis of the data collected from the informants taken from Oromia Education Bureau, OEB. Hereafter, they are called by their pseudonyms as Mr. Gemechu, Mr. Challa, Mr. Tolla, Mr. Muhammed and Mr. Negesso.

\section{Participants' involvement in the process of curriculum materials development}

The first question raised for the interviewed experts was about the participants being involved in development process of primary school science curriculum materials of the Region. Accordingly, all informants share similar views. In this regard, Mr. Muhammed explained that as to the participants' involvement in the process of curriculum development as follows:

The participants who took part in the primary school science curriculum development in Oromia region in general and the upper primary school basic science curriculum development process in particular were from Oromia Education Bureau, MoE who were serving as curriculum experts when the curriculum was designed; subject specialists from college and university. However, representative teachers, students and other peoples like parents and administrators were not involved in the process curriculum development; however, there have been practices of asking and incorporating their ideas, comments and interests in the curriculum although they are not physically present. Such gathering of suggestions from these parties have been through different ways particularly during pilot testing stage of the developed curriculum in the selected schools before massive implementation (Muhammed, 21/04/2018)

Adding, the researcher compared the result of the interview held with curriculum experts at Oromia Education Bureau with the result of the document analysis. The result of document analysis also showed that the participants involved in the process of curriculum development in primary school education were Experts from 
MoE, Experts in the Regional Education Bureau and subject area specialists from Colleges and Universities. No document was found indicating the involvement of representative teachers, students and society in primary school science curriculum in general and upper primary school basic science curriculum in particular.

Similarly, from the discussion held with the informants and the document analysis, it could be inferred that participants involved in primary school curriculum development process in general and upper primary school basic science curriculum material development process in particular were only experts from MoE, Experts from the Regional Education Bureau and subject area specialists from Colleges and Universities. Whereas, parents, teachers and students, have been totally ignored from participating in curriculum development process. The exclusion of the key stakeholders such as teachers of that particular level, students, parents, etc., disagrees with the advices of scholars like Taba (1962), ICDR (1999) and Ornestin and Hunkins (2004) who state that, incorporating needs and involving the participation of different concerned groups will help the curriculum to be successful. As to them, curriculum development is not an activity of a single individual or few individuals because the designed curriculum is going to be implemented and changed into reality in order to attain the objectives intended; for attaining these objectives parties like teachers, students, administrators, etc, in addition to curriculum experts should be involved.

\section{The model used in the development of upper primary school basic science curricula.}

In line with this, a question was forwarded to the curriculum experts as to the types of the curriculum development model that is used as a guideline for the primary school curriculum development process in general and upper primary school basic science curriculum development in particular. Regarding the model used in developing curriculum of primary education, one of the informants, Mr. Gemechu, explained that the model in use is not clear to him: "I have no idea as to what model we have been using since there is no clearly indicated and identified model that we have to use for the curriculum development; but we followed the curriculum development framework developed by the ICDR (1999) (Mr. Gemechu, 19/04/2018)."

On the other hand, other informants of the study like Mr. Muhammed, Mr. Negesso and Mr. Challa shared almost similar ideas as to uncertainty of the model used during the curriculum development process. Mr. Challa, for instance explained his views as following:

It is difficult for us to know exactly about the types of model used in the process of upper primary school basic science curriculum development. But, in the process of developing the curriculum we followed the procedures like: firstly, syllabus objectives were developed by contextualizing the syllabus objectives sent from MoE in line with the five objectives of the Ethiopian education and training policy namely (MoE, 1994); specifically to: develop the physical and mental potential and problem solving capacity of the individual by expanding education and in particular by providing basic education for all; bring up citizen who can take off and utilize resources wisely, who can trained in various skills by raising the private and social benefits of education; bring up citizen who can respect human rights stand for the well-being of people as well as for the quality of justice and peace, democratic culture and discipline; bring up citizen who differentiate harmful practices from useful ones, who seek and stand for truth, appreciate aesthetic and show the positive attitude towards the development and dissemination of science and technology in the society; and cultivate the cognitive, creative, productive and appreciative potential of the citizens by appropriately relating education to the environment and social needs. Thereafter, contents were selected and organized based on the stated objectives, methods, materials and evaluation criteria were sent in the curriculum for easy implementation of the curriculum by teachers and students (Mr. Muhammed, 19/104/2018).

Another respondent, Mr. Tolla has shared some of the opinions of the other informants, and he explained his views as follows:

Although I don't know the types of model in use for the curriculum development, we begun the task of curriculum work by specifying general objectives then proceed to breaking down into the specific objectives in line with the syllabus objectives developed by the MoE. Once the objectives are stated, the next step was the selection and organization of contents and learning experiences to be used for addressing the objectives (Tolla, 21/04/2018.)

In general, from the discussions made so far, the response of the respondents were mixed; where one of the respondents replied as the curriculum development framework developed by the ICDR (1999) was used as a model of curriculum development and majority of them do not clearly know the type of model used in curriculum development process. However, from the activities done by curriculum experts as responded for the questions seem similar with the objective model approach as shown by the (Tyler, 1949) and ( Taba, 1962), although they failed to conduct needs assessment before selection of objectives and contents. This process is more or less similar with the objective model, because, according to Tyler (1949) and Taba (1962) the objective model of curriculum development is based on the objectives that are stated at the very beginning. According to the advocators of this model, everything starts by formulating objectives that are going to be attained at the end of a certain program. 
The researcher used document analysis in order to triangulate the interview data with the results of document analysis. Accordingly, the result of document analysis showed that there was no evidence or written statement indicating the type of model used to develop the curriculum for primary education in general and upper primary school basic science curriculum in particular; rather than the implication showing the objective model. Thus, objective model is the one, which was widely claimed to be applied for curriculum development in the region.

From the above discussion with informants and document analysis, therefore, it is possible to conclude that even though there is no clearly and explicitly identified model used in developing the curriculum, it seems the objective model has been used in the development of upper primary school basic science curriculum with all its limitations.

3. Procedures followed in the upper primary school basic science curriculum materials development The other issue discussed with the curriculum experts was about the procedures followed in the development of the upper primary school basic science curriculum materials development process. In connection with this, two of the informants, Mr. Gemechu and Mr. Negesso explained the procedures followed in a similar way. Mr. Negesso, for example explained his views as:

First of all, we have discussed on the syllabus objectives sent to us from the MoE and we work to contextualize these objectives into the existing real condition of the region. By taking the syllabus prepared by the Ministry of Education in collaboration with curriculum experts of the MoE, the Oromia Education Bureau curriculum experts adapt the syllabus as a framework of the curriculum for primary education on the basis of the objective reality of our region, and prepared text books and teachers' guide from the syllabus. In addition, the curriculum development framework developed by the ICDR (1999) is used as a reference by the curriculum developer of the region (Mr. Negesso, 23/04/2018).

Regarding the issues under discussion, other informants, Mr. Challa and Mr. Muhammed, shared similar ideas. Mr. Challa, for instance, explained the processes to be followed in the curriculum development as follows:

First of all, curriculum experts from Oromia Education Bureau were called by the curriculum experts from the MoE to discuss and comment on the developed syllabi by the experts of the MoE (just one of the representative curriculum experts from all regions). Based on the syllabi prepared by the ministry of education in collaboration with representative of the region, experts at the Oromia Education Bureau in collaboration with Colleges and Universities prepared syllabi based on the objective reality of the region and translated it into "Afan Oromoo" and from that we prepared textbooks and teacher's guide. In the preparation of the teacher's guide and textbooks experts from the Region Education Bureau, teachers from Colleges and Universities prepare syllabi in line with the objective reality of the region and then translated it into Ofan Oromoo after which we write textbooks and teachers guide. In so doing, the syllabus flow chart was prepared and finally syllabus for each subject and each grade level were prepared. After doing all these, the developed curriculum was piloted in the selected schools of the region. After evaluation of the implemented curriculum in sample schools, corrections were made and then distributed to all schools of the region for the implementation (Mr. Challa, 21/04/2018)

In addition, one of the informants, Mr. Tolla replied as follows: "All the steps of the curriculum development process suggested by the ICDR, was used as a working model or framework for any curriculum in general and upper primary school basic science curriculum in particular (Mr. Tolla, 21/04/2018).”

In general, what has been exercised by the curriculum experts of Oromia Education Bureau regarding the process of development of the upper primary school basic science curriculum, first objectives are developed and then contents are specified. Then, subjects are discussed with the curriculum materials writers from Colleges and Universities. Then developed curriculum is piloted in the selected schools of the region. After evaluation of the implemented curriculum in sample schools, corrections are made and then distributed to the whole schools of the region for the implementation. However, none of the informants mentioned about the diagnosis of needs of the students, society and subject specialists in the selection of the precise objectives; by default, this indicates the absence of screening worthwhile objectives among many of the objectives that would be derived from the needs assessment as suggested by Tyler (1949).

\section{The specific steps followed in the upper primary school science curriculum development}

i. Sources of objectives

The curriculum experts at the Oromia Regional Education Bureau were asked about the type of specific steps they followed in the curriculum development process. To this end, one of the questions raised to the informants was about sources of objectives in the selection of the instructional objectives for the upper primary school basic science curriculum.

In line with this, all the informants (Mr. Gemechu, Mr. Challa, Mr. Negesso, Mr. Tolla, and Mr. Muhammed) shared similar ideas that objectives are taken from syllabus objectives and education policy of the country. For instance, Mr. Challa expressed his views as follows:

The objectives for any primary school curriculum in Oromia Regional state of Ethiopia in general and 
basic science curriculum in particular were taken from the objectives of the syllabus sent from the MoE prepared at the center in line with the existing national educational policy of the country. All the educational activities should reflect and maintain the uniformity and consistency of education among the entire regions (Mr. Challa, 21/04/2018).

In contrast to the above result, Ornstein and Hunkine (2004: 234) assert that, those stimulating with the design of the curriculum must clarify their philosophical and social views of society, subject matter/ knowledge and the individual learner or what are commonly called the sources of curriculum design. Attention must be given to how such sources will influence education. For this reason, it is essential for curriculum designers to identify their philosophical, psychological and social orientations. If they ignore philosophical, psychological and social questions, their curriculum design will have limited or confused rationales.

As the result, objectives of the upper primary school basic science curriculum are developed simply for the sake of formality and which in turn may not contribute to the needs and interests of the students; and lack scientific basis, only the criteria of matching or consistency with the national education were considered by the curriculum experts of the Oromia region; and the selection of objectives are irrelevant basis for the selection and organization of content and learning experiences of the curriculum and its materials. From this, it is possible to conclude that among many criteria used for the selection of objectives, only the criteria of matching or consistence with the policy of education of the country were considered by the curriculum experts at the Oromia Region without considering the other criteria.

Along with the information on selection of the objectives, data were gathered as to how the objectives selected were screened out to culminate into precise objectives which in turn serve as education objectives. To this end, very surprisingly, no informant raised about the issues of the needs assessment, from which the various objectives can be selected from, which is known as sources of objectives as contested by the Tyler (1949). The justification given by all interviewees were almost similar. In this regards, one of the informants, Negesso said:

We did not employ any screening devices/ mechanisms because the need assessment was already conducted by the MoE, while they were developing the syllabus objectives, and hence by default, no need of screening the objectives by the use of the psychological and philosophical screening devices. The objectives sent to us from the MoE are already screened out by their experts, and our task here is to contextualize and cascade the objectives into the existing condition of the region (Negesso, 23/04/2018).

From the justification of the respondents, it is possible to conclude that need assessment was already conducted by the MoE while they were developing the national syllabus objectives and by the default, no need of the applying the process of screening objectives by the experts in which the selection of the objectives is based on as Tyler (1949) contested.

\section{ii. Selection of contents and learning experiences}

The interviewees were asked how the contents and learning experiences for the upper primary school basic science curriculum were selected. To this end, two of the informants, Mr. Muhammed and Mr. Tolla, offered similar ideas that the selection of contents is based on the predetermined objectives. Mr. Muhammed, for instance, has put his views as follows: "We curriculum experts in the region have contextualized the already predetermined syllabus objectives set by the MoE as a basis for the selection of content and learning experiences (Mr. Muhammed, 19/04/2018)."

The other informants, Mr. Gemechu and Mr.Challa, also replied almost similar responses with the other informants in that the selection of contents was based on predetermined criteria. Mr. Gemechu, for example explained his views and read as: "The selection of contents and learning experiences have been made in line with such criteria as consistency with objectives, significance of contents and learning experiences to the real life situation of the students and society at large (Mr. Gemechu, 19/04/2018)."

In line with this, scholars such as Tyler (1949), Derebssa (2004), and Taba (1962) advise clear criteria for selection of contents and learning experience. For instance, Tyler (1949) advises the use of validity- consistence of contents and learning experiences with the objectives, significance, balance of breadth and depth, learn ability, and adaptability to the experience of learners. In contrary to the views of scholars Tyler (1949), Taba (1962) and Derebssa (2004), the Regional Education Bureau has ignored application of significance, adaptability and learnability, breadth and depth and feasibility of the contents and learning experiences as criteria.

From this, one could infer that the selection of the contents and learning experiences that are invalid and less applicable to the students and societies upon which the curriculum is to be applied, this is because the selection of contents and learning experiences is based upon the predetermined objectives and significance of the contents and learning experiences to the real life situation of the students and society at large.

iii. Organization of contents and learning experiences

After discussion as to how contents and learning experiences were selected, the researcher raised another question as to how these selected contents and learning experiences were organized. Accordingly, informants like, Mr. Tolla and Mr. Challa expressed that the organization of contents was based on the flow charts. Mr. 
Challa for instance, has said:

In order to maintain the relationships between the subjects along and across the grade level, we were guided by the syllabus flow chart. By the help of the syllabus flow chart, we maintained the relationship between contents of the subjects across the grade levels and different subjects within the same grade level (Challa, 21/04/2018).

The other informants, Mr. Gemechu and Mr. Negesso expressed that the organization of contents and learning experiences are based on the contextualized objectives and contents of the region. For instance, Mr. Gemechu has put his views as follows:

The selection of contents and learning experiences were guided by the contextualized objectives and contents in line with the context of the region. We organized the contents primarily by looking how the contents and learning experiences were organized in the national syllabus; and then led to organize the contents and learning experiences along the contextualized objectives and contents (Mr. Gemechu,19/ 04/ 2018).

From the views of the informants, it is possible to judge that the organization of contents and learning experiences of the upper primary school basic science curriculum development process in the region maintained the vertical and horizontal organization of contents and learning experiences, which in turn can be judged that mechanisms of organization of contents they used were congruent to the criterion used for the organization of content and learning experiences contested by Tyler (1949). Tyler (1949) contested that contents and learning experiences are organized by the use of the criteria and elements used for the organization of contents and learning experiences: continuity, sequence, and integration, which are known in maintaining the vertical and horizontal organization of contents and learning experiences.

\section{v. Evaluation of the curriculum development process}

The participants were interviewed, as to whether they believe what they did was good or not? Concerning this question, Mr. Negesso and Mr. Challa shared similar views that the curriculum developed should be always under review and subjected to revision. For instance, Mr. Negesso has put his views and read as: "We did our best, and we thought that all the scientific procedures were followed in the curriculum development process and hence our curriculum was good. But, it does not mean that this was the final. It should be always under review (Mr. Negesso, 23/04/2018).",

Other respondents like Mr. Muhammed and Mr. Gemechu also replied to similar ideas that the curriculum developed is good. Mr. Muhammed for example explained his views as follows:

As to me, the developed curriculum materials were good. Because the development process passed through the involvement of experts from the region and supervised by an expert from the Ministry of Education and representatives from the Addis Ababa university. As to the technical aspects incorporated into the curriculum materials, it is good consult the implementers, teachers and students and school directors. Teachers, students and school directors know more about the curriculum than the developers because they are the real implementers of the curriculum and know its problems (Mr. Muhammed, 19/ 04/2018).

From the responses of the interview informants, although they thought that it was good, they did not apply varieties of evaluation approach to the curriculum development process. It is the view of the researcher that it was advisable at least to follow the curriculum development framework developed by the ICDR (1999:32), stating that before massively implementing the curriculum it is unquestionable to implement the newly developed curriculum in some pilot schools and so that some adjustment were made based on the comments collected from the implementers like teachers, students and school directors into the region.

In sum, from the discussion held so far and the evidences drawn from the study revealed that the technical and social phases of curriculum design and development were overlooked, the role of stakeholders in the curriculum issue is not as satisfactory as expected, and the curriculum components of upper primary school basic science curriculum lack some more necessary course ingredients.

\section{vi. Challenges observed in developing upper primary school basic science curriculum}

Along with the major steps to be followed in the curriculum development process for the upper primary school basic science curriculum, data were gathered on factors affecting upper primary school science curriculum development process. To this end, all interviewees shared similar responses showing that there were a number of factors affecting the development process of curriculum. For instance, Mr. Challa has provided his views as follows:

Lack of professionals, time pressure, and shortage of budget, shortage of facilities and absence of training are among major factors that have been impeding the process of development of the grade 5 and 6 basic science curriculum in the Region. We have a lot of commitment like, training, committee work, administrative work, supervision, etc, that take much of our time in addition to the task of curriculum development. Payment for the preparation of the textbook which was made on the basis of page is so small, and indicates the less concern given for the preparation of quality curriculum; lack of budget for 
experience sharing (national or international); lack of incentive to motivate the curriculum materials writers are also major problems pertaining to the financial matters were few of the challenges in this regard (Mr. Challa, 21/04/2018).

In supporting these viable ideas, According to McNeil (2004), one of the factors affecting the process of curriculum development process is the adequacy of necessary materials and financial support, including sufficient time. The arrangement of adequate and properly arranged working space, necessary clerical staff, and travel funds need attention. All these need to be available for those who are engaged in the activity of curriculum materials development. Similarly, Derebssa (2004) mentions that some decisions have to be made before initiating curriculum development. There must be tangible resources; the required personnel and sufficient time should be available to allow reasonable expectation of success.

\section{Summary, conclusions, recommendations and suggestions for future studies}

This final section was about summary of the major findings, conclusions, recommendations and suggestions for future studies were made on the basis of analysis and interpretation of the study.

\section{Summary of major findings}

The main purpose of this study was to investigate upper primary school basic science curriculum materials development process in Oromia Regional State of Ethiopia. To this effect, after analysis and interpretation of data, the study came up with the following major findings in light of the basic research questions as indicated hereunder:

- Regarding the participants involved in upper primary school basic science curriculum developments in Oromia Regional State, findings of the study revealed that curriculum experts from the MoE as consultants, experts from Oromia Education Bureau, and teachers from different regional colleges and universities were the main participants. However, teachers, principals, students and parents were not involved in upper primary school basic science curriculum development process.

Concerning particular model followed, majority of the interviewees asserted that they were not given any type of model. However, from the procedures followed in the development of the curriculum, it can be possible to judge that the models used for the development was the objective model.

As the majority of the informants responded, the process and procedures of the curriculum development process for primary education in general and upper primary school basic science curriculum development in the Oromia region of Ethiopia in particular includes the following:

$\checkmark$ Developments of objectives were made by contextualizing syllabi objectives sent from the MoE, in line with the objectives of the Ethiopia education and training policy;

$\checkmark$ Based on the syllabi prepared by MoE as a framework and objectives developed by the regional education bureau, the experts develop syllabus for primary education based on contextual condition of the region;

$\checkmark$ From the syllabi prepared by the Oromia Education Bureau in line with the Federal Ministry of Education, Oromia Education Bureau prepares textbooks, teachers' guide and manuals;

$\checkmark$ Before the actual implementation of the prepared curriculum, the textbooks and teacher's guide were tested in some selected schools.

$\checkmark$ Based on the feedback obtained from the pilot, the curriculum materials are modified and finally made ready for implementation.

As majority of the respondents replied, the basis for the selection of contents and learning experiences, are based on the already prepared objectives of Ethiopian education and training policy and syllabus objectives sent from the MoE; consistency of the contents and learning experiences to the contextualized syllabus objectives developed by the region and to the real life situation of the students and society. However, balance of breadth and depth, learnability and adaptability to the experience of learners, feasibility and appropriateness of the contents to the developmental age level of the students were not used as a basis for the selection of contents and learning experiences.

Regarding the criteria for the effective organization of contents, learning experiences, activities and others, almost all the informants asserted that syllabus flowchart was developed, along and across the grade levels and different subjects within the grade level. From the responses of the experts, they are position that they employ the basic criterion like continuity; sequence and integration were considered for the effectiveness of the organization of the contents and learning experiences.

In sum, from the discussion held so far and the evidences drawn from the study revealed that the technical and social phases of curriculum design and development were overlooked, the role of stakeholders in the curriculum issue is not as satisfactory as expected, and the curriculum components of upper primary school basic science curriculum lack some more necessary steps that add the quality of materials. 
Along with the major steps to be followed in the curriculum development process for upper primary school basic science curriculum, majority of informants asserted that lack of professionals, time pressure as a result of lot of commitments in addition to the task of curriculum development process; lack of budget, inability to discuss with the students, teachers and society about the curriculum; absence of short term training for curriculum experts like national and international training, workshop, and discussion with the resource person on the curriculum development; lack of experience in the area of curriculum development and lack of facilities and material support are identified as the major factors affecting the effectiveness of upper primary school basic science curriculum development process in the Oromia Regional State.

\section{Conclusions}

In light of the basic research questions, data analyses, interpretations and summary of the major findings of the study, the following conclusions are forwarded.

Although encouraging attempts have been made to involve concerned bodies in curriculum development process like, experts from $\mathrm{MoE}$, experts from Oromia Education Bureau, teachers from regional colleges and universities, representatives of teachers, learners and the parents and other stakeholders did not participate at all. No matter how intelligently the curriculum plan may have been worked out by other groups, without teacher's participation, it is hardly possible to assume that it would be effective in actual classroom practice.

There was no clearly indicated and stated type of model used for upper primary school basic science curriculum development processes; and no document was found as to the type of model used. From the findings of the study, it can be concluded that although the model used in the development process seems to be objective model, the objectives of upper primary school basic science curriculum have not up to acceptable standards.

The contents selected in the curriculum materials under study have not been found to be fully appropriate with regard to the general criteria used for the selection of contents and learning experiences.

With regard to the organization of contents and learning experiences, syllabus flow chart was used as a mechanism to check the alignment of the contents and learning experiences along and across the grade levels. Thus, in so doing, continuity, sequence and integration of concepts, skills and values suggested in the curriculum materials under study have been found to be effective. However, the organization of the contents and learning experiences of the curriculum materials under the study were found to be of poor quality in that the exercises and activities suggested in the curriculum were not organized in a clear and logical sequence.

In general, the findings of the study revealed that the procedures followed in the development of basic science curriculum materials at Oromia Regional State didn't follow all the steps to be followed in curriculum development process, and thus, the result shows that there is a gap between the suggested upper primary school basic science curriculum and the intended curriculum currently implemented in the schools.

\section{Recommendations}

On the basis of data analyses, discussions, findings and conclusions made in the preceding part of this study, it is reasonable to forward the following recommendations.

a The curriculum development process is a team work and involves the coordination of different group of members or stakeholders. Therefore, it is recommended that the Oromia Education Bureau of Oromia, OEB in collaboration with the Ministry of Education should facilitate possible means to involve the representative teachers, students, parents and other concerned bodies in the curriculum development processes starting from planning to evaluation.

a The findings of the study revealed that there is no clearly indicated model and theoretical framework that guides the development of the basic science curriculum in Oromia Regional State of Ethiopia. Therefore, it is recommended that the OEB in collaboration with MoE need to set a model or a theoretical framework that govern the development of the curriculum at any level of education in general and basic science curriculum in particular.

a The findings of the study show that the basic science curriculum development process fall short in meeting the purpose for its being designed as per the education and training policy of the country, Ethiopia. Therefore, it is recommended that the REB in collaboration of the MoE need to revise the syllabus following the basic procedures of the curriculum development process stipulated by policy education.

2. Suggestions for future study

This study focuses on the investigation of upper primary school basic science curriculum development processes 
in Oromia Regional State of Ethiopia. To this end, it may be worthwhile to undertake further studies in the following areas in order to understand some of the issues untouched in this study.

Firstly, further study could be conducted on the other curriculum materials that are designed for the same grade level and other levels in the series within the region or other regions of the country in order to observe the nature and appropriateness of the curriculum to the needs and interests of the students.

Secondly, the developed curriculum can be implemented by the teachers. The effectiveness of teachers can depend on the appropriateness of the curriculum material they were used in their training. Therefore, further research should also be conducted on the curriculum materials development process used for the preparation of the primary school science teacher.

\section{REFERENCES}

Ayalew, Hassen (2006). An evaluation of grade $7^{\text {th }}$ and 8th the geography syllabus in Addis Ababa. MA thesis unpublished, Addis Ababa Univrsity

Best, J.W. and Kahn, J. R. (2003). Research in Education (9th Ed). New Delhi: Prentice Hall of Inc. Private Limited.

Creswell, J. W. (2009). Qualitative Inquiry and Research Design: Choosing Among Five Approaches. California: SAGE publication.

Dawit, Mekonnen (1999). An evaluation of an implementation of the seventh grade English syllabus in Easter Gojjam. Addis Ababa: MA thesis unpublished.

Derebssa, Dufera (2004). Principles of Curriculum Development. Addis Ababa: Institute of Educational Research, IER.

Dereje, Abdi (2007). An assessment of the status of the students centered teaching methods and assessment practices teaching science Oromia (un published). Addis Ababa University.

ICDR (1999). Teachers Education Handbook. Addis Ababa: ICDR (Unpublished).

Kothari, C.R. (2004). Research methodology: Methods and Techniques ( $2^{\text {nd }}$ ed). New Delhi: New age international publisher.

Lockheed, M. E. and Verspoor, A.M. (1991). Improving Primary Education in Developing Countries. Washington, D.C.: Oxford University Press.

McNeil, John (1996). Curriculum: A comparative introduction ( $3^{r d}$ ed.). Boston: Little, Brown and Company.

OEB (2014/15). Educational Statistics Annual Abstract. Finifine.

Ornstein, A. C. and Hunkins (2004). Curriculum, Foundations, Principles, and Issues (4th ed.) New York: Pearson Education, Inc.

Prasad, Janardan (2006). Education and Society: Concepts, Perspectives, and suppositions. New Delhi: Kanishka publishers.

Reichel, M. and Ramey, M. A. (1987). Conceptual frameworks for bibliographic education: Theory to Practice. Littleton, Colorado: Libraries Unlimited, Inc.

Shiundu, J. S. and Omulando, S.J. (1992). Curriculum: Theory and Practice in Kenya. Nairobi: Oxford

Solomon, Areaya (2008). Policy Formulation Curriculum Development and Implementation in Ethiopia. Addis Ababa University: Addis Ababa Book Centre.

Taba, H. (1962). Curriculum Development: New York: Harcourt, Brace and World. Inc.

TGE (1994). Education and Training Policy. Addis Ababa: EMPDA

Tyler, R.W (1949). Basic Principles of Curriculum and Instruction. Chicago: University of Chicago Press.

UNESCO (2000). World Education Forum. Dakar Framework for Action. UNESCO Press

Vygotsky, Lev (1978). Mind in Society. London: Harvard University Press.

Yin, Robert k. (2003). Case Study Research: Design and Methods. Beverly Hills, CA: SAGE publishing. 